\title{
Escola como extensão da família ou família como extensão da escola? $O$ dever de casa e as relações família-escola*
}

\author{
Maria Eulina Pessoa de Carvalho
}

Universidade Federal da Paraíba, Centro de Educação
Embora pouco estudado, ou problematizado, o dever de casa é uma prática cultural que há muito integra as relações família-escola e a divisão de trabalho educacional entre estas instituições. Pode ser visto como uma necessidade educacional, reconhecida por pais e professores, sendo concebido como uma ocupação adequada para os estudantes em casa; pode ser considerado um componente importante do processo ensino-aprendizagem e do currículo escolar; e pode ser concebido como uma política ${ }^{1}$ tanto da escola e do

* Este texto retoma um capítulo da minha tese de doutorado, posteriormente publicada em livro (De Carvalho, 2000). As citações da bibliografia em língua inglesa foram por mim traduzidas. Apresentado no GT Sociologia da Educação, durante a $26^{a}$ Reunião Anual da ANPEd, realizada em Poços de Caldas, MG, de 5 a 8 de outubro de 2003.

${ }^{1}$ Os termos política (politics) e política pública/educacional (policy) serão usados aqui em sentidos próximos e articulados, como política-prática, compreendendo discursos-práticas formais e informais, explícitos e implícitos, envolvendo vários atores sociais, além das diretrizes governamentais; como as escolhas sistema de ensino, objetivando ampliar a aprendizagem em quantidade e qualidade, para além do tempoespaço escolar, quanto da família, visando estimular o progresso educacional e social dos descendentes.

Tradicionalmente, o dever de casa é considerado uma estratégia de ensino: de fixação, revisão, reforço e preparação para aulas e provas, na forma de leituras e exercícios. Seu conteúdo, geralmente, restringe-se ao currículo escolar, incluindo às vezes eventos familiares e comunitários, ou programas de televisão, como atividades de enriquecimento curricular ou estratégia de conexão das matérias escolares com a vida cotidiana. Nos aspectos psicológico e moral, tem sido justificado pela construção da independência, autonomia e responsabilidade do estudante por meio do desenvolvimento de hábitos de estudo e pontualidade. Finalmente, como uma política (mais ou menos

concretas e estratégias de obtenção de poder ou controle de gestores, pesquisadores, professores, pais e estudantes, cuja combinação complexa gera uma teia de cursos de ação que não são a realização automática da agenda oficial. 
explícita) de formalização da parceria escola-família, o dever de casa tem sido considerado uma panacéia para melhorar o aproveitamento escolar.

Concebido como parte integrante do processo ensino-aprendizagem, o dever de casa não apenas afeta seu planejamento e implementação, e, portanto, o trabalho docente, mas afeta também a vida dos estudantes fora da escola e sua rotina familiar, pois supõe a conexão entre as atividades de sala de aula e de casa, e uma estrutura doméstica adequada apoiando as atividades escolares. Assim, como o principal meio de interação família-escola, o dever de casa passa, de uma política tácita informal desenvolvida por famílias e escolas (e seus agentes), a uma política formal que articula os esforços educativos destas instituições. Nesse sentido, o foco no dever de casa pode servir como uma janela para olhar as relações família-escola e abordá-las de vários ângulos.

Há vários aspectos interessantes da política-prática do dever de casa: relacionados a concepções curriculares, processos pedagógicos e ao trabalho docente, vistos como dependentes da contribuição da família; e relacionados à evolução, especialização funcional e entrelaçamento das práticas educativas de famílias e escolas, e ao dever de casa dos pais, mais precisamente, das mães. Por um lado, a concepção e prática predominante do dever de casa como trabalho escolar transferido para casa pode constituir uma estratégia defensiva contra a cobrança da responsabilidade estatal/escolar, de prover (suficiente e adequada) educação formal. Por outro lado, constitui uma ilustração pertinente de violência simbólica (Bourdieu \& Passeron, 1975) via extensão da autoridade pedagógica da escola (incumbida da função de imposição do arbitrário cultural dominante, um determinado currículo) ao lar em outras palavras, um caso de regulação da vida privada pela política pública, através da instrução ou disciplinamento da família pela escola, via prescrição, explícita e implícita, de práticas parentais. Isto é claramente visível quando o dever de casa se torna uma estratégia de inclusão de famílias de minorias e trabalhadores imigrantes (como nos Estados Unidos) e grupos de baixa renda (tanto lá como no Brasil).
Há que se levar em conta, ainda, a perspectiva da família, segundo a qual o dever de casa pode ser visto como uma necessidade legítima e uma prática desejável, ou como um fardo e uma imposição, dependendo de condições materiais e simbólicas variáveis. Certas condições e aspirações familiares podem ser investidas em políticas-práticas a favor do dever de casa pelos pais como atores individuais, em consonância com as políticas-práticas escolares (isto é, as solicitações de apoio dos pais), ao passo que sentimentos contrários, baseados em dificuldades de aderir ao dever de casa, tendem a permanecer velados no contexto de relações de poder escola-família (misturadas a relações de classe, raça-etnia, gênero e idade) desfavoráveis aos pais.

Assim, o dever de casa propicia múltiplas abordagens, necessariamente complexas. Neste texto, apresento um panorama da política-prática do dever de casa, nos Estados Unidos e no Brasil, e levanto algumas de suas implicações familiares e de gênero.

\section{História da política-prática do dever de casa e a parceria família-escola}

Meu interesse pela questão do dever de casa surgiu da minha própria experiência como mãe e professora de pedagogia, ao comparar experiências escolares no Brasil e nos Estados Unidos. No contexto brasileiro da jornada escolar de meio período, percebia a família na base tanto do sucesso quanto do fracasso escolar, ao compensar (ou não) as deficiências escolares e as dificuldades dos estudantes, oferecendo (ou não) alguma forma de reforço escolar, conforme a classe social (capital econômico e cultural) e o tipo e qualidade da escola (privada ou pública, mais ou menos exigente). No Brasil, meus filhos freqüentaram inicialmente escolas alternativas que não adotavam dever de casa porque atendiam uma clientela de mães profissionais, ${ }^{2}$ posteriormente, ao mudarem para uma

\footnotetext{
${ }^{2} \mathrm{O}$ marketing de uma dessas escolas era: "Aqui seu filho ou
} filha aprende tudo que precisa aprender, por isso não mandamos dever de casa". 
escola tradicional, tive de recorrer a uma professora particular em casa para acompanhar o dever de casa. Nos Estados Unidos, não esperava que escolas públicas de jornada integral, superequipadas e contando com professores bem qualificados, adotassem dever de casa; portanto, minha surpresa e dificuldades como chefe de família/mãe de três crianças, sem apoio de família extensa, gerou interesse no seu estudo.

O dever de casa não tem sido objeto de pesquisa, aparecendo como um tópico periférico em análises de fatores do rendimento acadêmico e das interações entre a escola e a família. Visto simplesmente como uma boa idéia que cumpre incentivar (e não questionar), não tem sido problematizado pela pesquisa. A pesquisa educacional americana apresenta clara preponderância de avaliações favoráveis à produtividade do dever de casa no aproveitamento escolar (Clark, 1993; Henderson \& Berla, 1994; ERIC Abstracts Data Base, 2000), concentrando-se em áreas como dificuldades de aprendizagem, programas de educação compensatória, motivações e valores das famílias e dos estudantes, e relevância conceitual da tarefa, no contexto do planejamento e avaliação do ensino.

O impacto positivo do dever de casa no aproveitamento escolar (como variável correlacionada ao desempenho em testes padronizados) ainda não foi e dificilmente pode ser estabelecido empiricamente ou experimentalmente, de forma conclusiva, porém poucos estudos explicitam isto ao fazerem recomendações favoráveis à sua adoção. Não há pesquisa substancial para corroborar uma relação entre alto desempenho, tempo dedicado ao dever de casa, tipos de tarefas e estilos de acompanhamento, considerando níveis e séries escolares, objetivos curriculares, matérias, níveis de habilidade dos estudantes e características individuais, socioeconômicas e étnicas. Assim, este parece ser um caso de viés cultural direcionando escolhas de pesquisa e política educacional.

Alguns pesquisadores brasileiros (atrelados à formulação de políticas financiadas pelo Banco Mundial) vêm reproduzindo a lógica da pesquisa e política educacional americana sobre as relações família-escola
(Projeto Nordeste, 1997). As análises dos resultados do SAEB 2001 também apontam "o hábito de fazer a lição de casa no rendimento do aluno" (Brasil, Ministério da Educação, INEP, 2003).

A hipótese de que quanto mais dever de casa, maiores notas nos testes tem base na experiência social. Porém, os estudos de correlação entre participação dos pais na vida escolar dos filhos e aproveitamento escolar medido por testes padronizados, ao chamarem a atenção para a influência do dever de casa na aprendizagem e sucesso escolar, não explicam que a adesão dos pais ao dever de casa representa investimento de capital cultural como estratégia de reprodução familiar e social (Bourdieu, 1986), sendo seu rendimento fruto da vantagem do lar (Lareau, 1993). A questão de política educacional é se é viável incentivar a participação dos pais (cujos filhos vão mal na escola) via dever de casa, precisamente daqueles que não participam por falta de capital econômico (tempo livre, dinheiro para pagar aulas de reforço) e cultural (cultura acadêmica e conhecimento atualizado dos conteúdos curriculares).

Nesse contexto, são raros os estudos que problematizam o dever de casa, apontando limites e dificuldades (nos Estados Unidos, Corno, 1996; Natriello, 1997; Kralovec \& Buell, 2000; De Carvalho, 2000; no Brasil, Paula, 2000). São novidade os estudos qualitativos (sociológicos, antropológicos) das relações família-escola, particularmente das práticas educativas e estratégias de escolarização das famílias, tanto nos Estados Unidos (por exemplo, Lareau, 1993; McClain, 1997), como no Brasil (por exemplo, Nogueira, Romanelli \& Zago, 2000; Franco, 2002).

A abordagem histórica é interessante para a análise do dever de casa como instrumento de interação entre família e escola. Nos primórdios da escolarização compulsória, as escolas que serviam às comunidades/famílias rurais e urbano-industriais não enviavam trabalho escolar para casa, porque então as crianças e jovens participavam do trabalho real por razões de sobrevivência. $\mathrm{O}$ dever de casa escolar surgiu como uma ocupação apropriada para os estudantes das classes médias (cuja reprodução estava asso- 
ciada ao sucesso acadêmico) e tornou-se parte do estilo de vida dos grupos sociais escolarizados e daqueles que valorizavam a escolarização como estratégia de mobilidade social ascendente.

Nos Estados Unidos, de acordo com Gill e Schlossman (1995), a história do dever de casa, ao longo do século XX, revela uma disputa quanto à sua importância no discurso e na política educacionais, como resultado não apenas de debates sobre concepções pedagógicas, mas também de pressões das famílias. Sua quantidade e formas, por exemplo, têm sido reguladas por políticas escolares na medida variável que foi visto como uma estratégia de elevação do nível acadêmico ou como uma interferência na vida familiar e nas atividades sociais dos estudantes. ${ }^{3}$

O Movimento Progressista, que teve Dewey como expoente, não apoiava políticas de dever de casa, associadas aos métodos de ensino tradicionais. Antes da Segunda Guerra, muitos sistemas de ensino locais aboliram o dever de casa declaradamente para desencorajar a memorização e propiciar a utilização mais criativa do tempo fora da escola pelos estudantes e suas famílias. A pesquisa da época, expressando claramente os valores da classe média, objetivava demonstrar que o dever de casa não era apenas inútil para o aproveitamento escolar, mas prejudicial à saúde das crianças (Gill \& Schlossman, 1995). Na década de 1950, porém, no contexto da Guerra Fria, venceram as posições conservadoras favoráveis ao dever de casa: a política educacional renovou a ênfase na excelência acadêmica, atendendo também às aspirações das classes médias por qualidade (distinção) educacional. Há evidência de que o dever de casa já se tinha tornado, então, parte integral do trabalho escolar e uma política escolar formal (ERIC Abstracts Data Base, 2000).

${ }^{3}$ De acordo com a perspectiva liberal; numa perspectiva socialdemocrática, Eugene C. Brooks, um professor-pesquisador da Carolina do Norte, havia reconhecido, em 1916, que o dever de casa reproduzia a desigualdade social e proposto que os professores assumissem sua supervisão no lugar dos pais (Rothstein, 2001).
Na década de 1960, durante o Movimento pelos Direitos Civis, cresceu a crença na importância do dever de casa, a partir de estudos comparativos do desempenho de estudantes de diferentes grupos étnicos e condições socioeconômicas. Os com baixo aproveitamento escolar eram pobres, pertencentes às minorias étnicas (negros e hispânicos) e a famílias monoparentais, em desvantagem econômica e culturalmente despreparados para aproveitar os recursos sociais; os com alto aproveitamento escolar vinham de famílias estáveis, brancas e de classe média, que tinham incorporado a educação formal ao seu estilo de vida ou como meio de ascensão social. Assim, os primeiros tornaram-se alvo de políticas educacionais compensatórias objetivando melhorar o ambiente de aprendizagem do lar e a cultura familiar, através da combinação de dever de casa e educação parental, sob a bandeira da eqüidade (Scott-Jones, 1984, 1987). Todavia, na década de 1970, o dever de casa foi esquecido ou minimizado na política e prática educacionais (Gill \& Schlossman, 1995).

Na década de 1980, com a publicação de Uma nação em risco (National Commission on Excellence in Education, 1983), que creditava o declínio político, econômico e moral dos Estados Unidos a uma pedagogia suave (Gill \& Schlossman, 1995), as posições a favor do dever de casa mais uma vez se tornaram hegemônicas. Os estudos comparativos internacionais reforçavam a percepção da importância do ambiente familiar e das práticas de dever de casa: os estudantes japoneses, chineses e taiwaneses tinham melhor desempenho em testes padronizados e faziam mais dever de casa do que os estudantes americanos (Stevenson \& Stigler, 1992). Embora a pesquisa, de modo geral, fosse escassa e inconclusiva (Epstein \& Pinkow, 1988), o senso comum baseado na tradição do dever de casa e a ideologia dos valores familiares $e$ trabalho duro convergiam para a ênfase no dever de casa como estratégia para aumentar a produtividade escolar diante da urgência de ultrapassar os concorrentes econômicos, de acordo com a política de hegemonia internacional. Há evidências da expansão das políticas formais de dever de casa durante a déca- 
da de 1980, em todo o país, no contexto de reformas visando a excelência acadêmica (Chubb \& Moe, 1990; ERIC Abstracts Data Base, 2000).

A retórica educacional da década de 1990, seguindo (ou resistindo) a tendência de privatização e produtividade educacional, acentuou a responsabilidade e escolha da família (alternativamente, o empoderamento e participação dos pais na reforma da escola), propagando a correlação entre aproveitamento escolar (especialmente em matemática e ciências), competitividade individual (melhores empregos), e competitividade internacional (liderança político-econômica mundial dos Estados Unidos) (Arbanas, 1994; Ingham Intermediate School District, 1995). Diretrizes oficiais passaram a prescrever o dever de casa regular como uma estratégia para melhorar o desempenho acadêmico (Office of Educational Research and Improvement, 1992, 1996), estendendo o alcance da política educacional ao lar: as sugestões de limitar o tempo de televisão, estimular a leitura e acompanhar o dever de casa, claramente, transferem a responsabilidade pelo aprendizado do currículo escolar para a esfera parental. A parceria família-escola tornou-se a oitava meta da educação nacional do Governo Clinton, que prescreve a participação dos pais no desenvolvimento social, emocional e acadêmico das crianças (National Education Goals Panel, 1995).

As escolas americanas estão adotando políticas de dever de casa explícitas e amplas, definindo concepção, expectativas da escola e obrigações dos pais. Um levantamento nacional de políticas de dever de casa nos distritos escolares, feito por Roderique et al. (1994), revelou que 35\% tinham uma política de dever de casa naquele momento, incluindo: informação aos pais sobre regulamentos do dever de casa; especificação dos tipos de tarefas (preparação para aulas, exercícios, conclusão de tarefas iniciadas em classe e atividades de extensão); orientações quanto ao feedback dos professores (conceitos, elogios, notas e pontos de incentivo); explicitação dos papéis esperados dos pais em relação ao processo do dever de casa (proporcionar espaço e tempo, monitorar a conclusão das tarefas e assinar o trabalho completo); especificação de freqüência (três a quatro noites por semana), quantidade de tarefas diárias (com aumento progressivo conforme o nível de ensino), e mecanismos de comunicação casa/escola. Eis um exemplo de política de dever de casa adotada pelo Distrito Escolar dos meus filhos:

Definição:

O dever de casa refere-se a uma tarefa a ser completada fora do horário escolar, de preferência em casa. Estas tarefas mantêm os pais informados e envolvidos na aprendizagem de sua criança.

\section{Política:}

O dever de casa bem escolhido e claramente comunicado é uma parte integral do processo de instrução. $\mathrm{O}$ dever de casa será relevante e desafiante.

As tarefas de casa deverão revisar, reforçar ou estender a aprendizagem de sala de aula proporcionando prática e aplicação do conhecimento obtido; ensinar aos estudantes responsabilidade e habilidades de organização; promover uso do tempo inteligente e ordenado; e proporcionar oportunidades para atividades de enriquecimento.

As/os professoras/es deverão incluir dever de casa apropriado aos estudantes e às suas necessidades educacionais. Deverão levar em conta as tarefas passadas por outros professores, as diferenças individuais dos estudantes, e outros fatores que possam afetar o lar como uma extensão da sala de aula.

As conseqüências de não completar o dever de casa serão manejadas pelos/as professores/as individualmente. Os/as professores/as poderão deter um/a aluno/a para completar o dever de casa após as aulas [...] os estudantes devem ser avisados de antemão e, portanto, serão responsáveis por avisar aos pais. ${ }^{4}$ (East Lansing Educational Foundation, 1996, p. 14, grifos meus)

\footnotetext{
${ }^{4}$ Nesse caso, as crianças não voltariam para casa no horário
} normal no ônibus escolar; às vezes, em alguns dias da semana, havia um ônibus tardio, mas, caso não houvesse, os pais teriam de buscar os filhos na escola. 
De acordo com Rothstein (2001), o tempo de dever de casa para estudantes da escola elementar cresceu $50 \%$ nas últimas décadas nos Estados Unidos. Como pude constatar, de 1993 a 1997, algumas escolas investiam na política do dever de casa com mecanismos como: contratos especificando as obrigações quanto ao dever de casa, assinados pelo estudante e pelos pais; caderneta de registro do acompanhamento do dever de casa pelos pais (parent homework record); e homework hotlines - assistência ao dever de casa por telefone depois das aulas. ${ }^{5}$ Aparentemente, não havia vozes contrárias, com exceção da proposta de "abolição do dever de casa" de Garrett Redmond, membro do Conselho Escolar em Half Moon Bay, Califórnia (Gill \& Schlossman, 1995), tratada como uma excentricidade.

Uma consequiência deste tipo de política é responsabilizar os pais formalmente pela falta do dever de casa, ensejando disputas judiciais entre famílias e escolas. Em 2/10/1996, o jornal Detroit Free Press, por exemplo, tinha como manchete: "Distrito escolar torna detenção uma questão familiar” (Murphy, 1996). $\mathrm{O}$ artigo relatava que o distrito policial havia intimado os pais a comparecerem à detenção na manhã do sábado para fazer o dever de casa com os filhos insubordinados. E antecipava medidas legais de responsabilização dos pais "para ajudá-los a identificar nos filhos padrões de comportamento indesejáveis antes que se tornem problemas maiores", que iam de freqüência a palestras sobre "como criar melhor os filhos" a prisão

${ }^{5} \mathrm{Na}$ bibliografia americana há poucas referências a políticas/programas alternativos de acompanhamento do dever de casa, indicativos dos limites de algumas famílias para cumprirem tal obrigação: programas de extensão da jornada escolar (curiosamente denominados Dever de casa na escola) e centros de dever de casa nas bibliotecas públicas, para estudantes em situação de risco (ERIC Abstracts Data Base, 2000). Recentemente, na tentativa de reduzir o impacto da classe social sobre o aprendizado escolar, surgiram iniciativas como os Beacons, na cidade de Nova York, e os Twenty-First Century Community Learning Centers, nacionalmente, na administração Clinton (Rothstein, 2001). por 90 dias (e multa de quinhentos dólares), no caso de a detenção não ser cumprida (Murphy, 1996).

Em 24/11/2000, o jornal The New York Times trouxe a seguinte reportagem: "Boletins, desta vez para os pais e as mães”, enfocando a política de avaliação do envolvimento dos pais adotada pelo sistema de escolas públicas de Chicago, como reação à pressão destes sobre as escolas para melhorar o ensino, e como tentativa de assim responsabilizá-los também. A idéia declarada é mudar a cultura do lar, de forma que os pais desejem tirar boas notas para dar bom exemplo aos filhos. Algumas escolas adotaram o $\mathrm{Bo}$ letim de Envolvimento dos Pais com conceitos; outras, as listas de tarefas diárias (como revisar o dever de casa, ler para os filhos, levá-los à escola pontualmente e verificar se carregam os materiais necessários), que os pais devem completar e devolver assinadas, diariamente. A medida gerou reações favoráveis de comunidades cuja cultura reverencia a autoridade dos professores, e contrárias, tanto de pais quanto de professores que acham que dar notas aos pais poderá envenenar suas relações (Schemo, 2000).

A trajetória da política-prática do dever de casa nos Estados Unidos tem ressonâncias na política educacional brasileira recente. A tradição do dever de casa na nossa cultura escolar, sobretudo nas escolas privadas, está formalizando-se na política educacional. Ao estudar a construção histórica do dever de casa no discurso didático-pedagógico, particularmente nos manuais didáticos e na Revista Nova Escola, Paula (2000) constata que sua prescrição tem sido intensificada, nos últimos anos, com ênfase na responsabilidade, autonomia e eficácia.

Por exemplo, o auxílio dos pais e da comunidade na instrução, e a adoção de deveres de casa freqüentes, como "fatores determinantes da eficácia escolar" (Heneveld, 1994, p. 35-36), são prescrições do Projeto de Educação Básica para o Nordeste, patrocinado pelo MEC e pelo BIRD para melhorar a qualidade da educação fundamental na região. A aptidão para aprender, resultante do apoio eficaz dos pais e da comunidade, é definida pelos seguintes indicadores: evidência de que leituras, conversações e brincadeiras dirigidas ocorrem 
no lar, pressupondo a conexão entre práticas educativas familiares e currículo escolar. Auxiliar na instrução significa apoiar e monitorar os deveres de casa, servir como tutor, fonte de informações e audiência em relação ao trabalho escolar dos estudantes. Deveres de casa freqüentes são prescritos a partir da quarta série, com conteúdo adequado à idade dos alunos e ao ambiente familiar (Heneveld, 1994).

O MEC instituiu o Dia Nacional da Família na Escola e publicou, em 2002, a cartilha Educar é uma tarefa de todos nós. Um guia para a família participar, no dia-a-dia, da educação de nossas crianças (Brasil, Ministério da Educação, 2002), seguindo uma tendência global de política educacional neoliberal de formalização da participação dos pais na escola. No nível local, esta orientação começa a se formalizar nas escolas públicas, pois expressa uma concepção cultural do dever de casa como uma prática desejável, há muito adotada pelas escolas particulares. A Escola Municipal Professor Agostinho Fonseca Neto, de João Pessoa, por exemplo, elaborou a Cartilha Aprendendo com Carinho "com a finalidade de mostrar às pessoas que formam a comunidade escolar professores, funcionários, estudantes e, especialmente, pais e mães de alunos - como o envolvimento dos pais na aprendizagem dos filhos, em casa e na escola, pode melhorar o seu desempenho na escola e na vida" (João Pessoa, Secretaria de Educação e Cultura SEDEC, 2002, p. 3).

\section{Implicações familiares e de gênero}

Nos Estados Unidos, como sugerem HooverDempsey e Sandler (1997), o dever de casa faz parte da própria definição cultural do papel parental. Assim, a retórica do envolvimento dos pais na educação dos filhos não apenas coloca o dever de casa como obrigação moral, mas até mesmo anula a distinção entre dever de casa e lazer familiar. Contraditoriamente, ao mesmo tempo em que se espera que a educação doméstica apóie o currículo escolar, pouco se reconhece o dever de casa dos pais. Até parece que os benefícios do dever de casa derivam apenas do de- sempenho independente do estudante, como é sugerido pela prescrição (baseada em pesquisa) do órgão federal encarregado da educação americana:

Tarefas de casa efetivas não apenas suplementam as lições de classe; elas também ensinam os estudantes a serem aprendizes independentes. O dever de casa proporciona aos estudantes experiência em seguir instruções, fazer julgamentos e comparações, levantar novas questões para estudo, e desenvolver responsabilidade e autodisciplina. (U.S. Department of Education, 1987, p. 53, grifos meus)

Quem ensina em casa? De acordo com a retórica anterior, é o dever de casa que ensina. Omite-se, assim, que a experiência propiciada pelas sessões de dever de casa no ambiente doméstico é assistida pelos pais e familiares e requer considerável dispêndio de tempo e emprego de habilidades pedagógicas, constituindo uma segunda jornada de trabalho deles (Rothstein, 2001).

De acordo com Bowditch (1993), o atual movimento a favor do dever de casa determina uma curiosa divisão de trabalho entre professores e famílias:

Basicamente, as tarefas cobradas dos/as professores/ as, implícita ou explicitamente, são limitadas a apresentar informação e cobrir a matéria; às famílias, o que significa na maior parte das vezes as mães, são atribuídas as tarefas de motivar os estudantes e proporcionar o tempo, o espaço e a atenção ou assistência extracurricular de modo a assegurar que a aprendizagem aconteça. (p. 178, grifos do original)

Minhas alunas de pedagogia da Universidade Federal da Paraíba, professoras do ensino fundamental, definem assim os alunos que fazem os deveres de casa: participantes, atentos, têm ajuda, têm pais presentes, interessados, com boas condições financeiras e escolarizados. Das 23 alunas que responderam um questionário sobre visões e práticas acerca do dever de casa em fevereiro de 2003, 17 adotam dever de casa e apenas uma afirmou: "Não costumo passar deveres de casa, pois trabalho em um bairro carente $\mathrm{e}$ 
vejo que os pais trabalham o dia todo e não têm tempo ou não sabem ajudar os filhos".

Todavia, embora as condições para implementar e atingir os objetivos do dever de casa dependam das condições domésticas e familiares, a concordância dos pais sobre o valor do dever de casa tem sido tomada como um dado, como é atestado pela existência de poucos estudos sobre a questão (ERIC Abstracts Data Base, 2000). Há três condições necessárias aos pais para realmente acompanharem o dever de casa: tempo livre, conhecimento sobre as matérias escolares e pedagogia, e vontade e gosto. Assim, a política-prática do dever de casa baseia-se nos seguintes pressupostos:

- pais têm tempo para criar oportunidades de aprendizagem em casa, organizando e adaptando continuamente o ambiente doméstico para atender demandas escolares (providenciar materiais, assistir trabalhos de grupo nos fins de semana etc.), tempo que sobra do atendimento de suas próprias necessidades, obrigações e opções quanto à divisão do trabalho doméstico, horários de descanso, programas de lazer, com os quais o dever de casa não interfere;

- pais gostariam de se atualizar em relação ao currículo escolar ou voltar à escola, a fim de participar do projeto da educação pública ou do desenvolvimento dos seus filhos, e portanto a escola deveria investir em orientação/treinamento de pais para acompanhar os deveres de casa. ${ }^{6}$

A falta dessas condições é enfrentada por duas estratégias retóricas. A primeira é o apelo moral do discurso do sucesso versus fracasso escolar relacionados ao apoio ou negligência dos pais. Nessa perspectiva, o dever de casa é até mesmo apresentado como

${ }^{6}$ Não estou criticando iniciativas de educação/alfabetização de adultos combinadas à educação infantil, mas duvidando de uma política que condicione o sucesso escolar dos estudantes à reeducação dos pais. uma oportunidade de convivência positiva entre pais e filhos e de coesão familiar, na retórica americana. A segunda refere-se à tentativa curricular de conectar o conhecimento escolar à vida cotidiana, a exemplo, nos Estados Unidos, dos programas "Matemática em Família" e "Ciências em Família" (Programs for Educational Opportunity, 1995), com oficinas destinadas a "ajudar os pais/mães e as crianças a aprenderem matemática e ciências juntos" e de forma divertida, utilizando "situações e materiais comumente encontrados em casa". Por meio dessa estratégia, os lares tornamse salas de aula, os pais tornam-se simultaneamente professores e estudantes, e a educação infantil se combina com a educação de adultos. É esse exatamente o espírito da cartilha do MEC Educar é uma tarefa de todos nós. Um guia para a família participar, no diaa-dia, da educação de nossas crianças (Brasil, Ministério da Educação, 2002). ${ }^{7}$

Os discursos a favor do dever de casa englobam duas concepções e possibilidades: atividades de aprendizagem em casa, intencionalmente envolvendo os pais e atividades que os estudantes podem desempenhar independentemente. Porém, as mães sabem que a construção da independência é um processo gradual e que a maioria dos estudantes não consegue dar conta do dever de casa sem ajuda. Enfim, as condições mencionadas apontam para um modelo de família particular, que conta com um adulto (geralmente a mãe) com tempo livre, conhecimento e uma disposição especial para educar. Há uma continuidade entre a feminização do magistério e a educação doméstica, e o dever de casa tem dependido da doação do tempo (trabalho gratuito) das mães, sobrecarregando aquelas que exercem trabalho remunerado fora de casa.

Como argumenta Bowditch (1993), "a retórica do envolvimento dos pais [...] assume, legitima e tenta impor um modelo normativo particular de família [...] que tem se tornado cada vez menos representativo das famílias americanas [e brasileiras] em todas as classes

${ }^{7}$ É uma cartilha bem elaborada, porém nem todos os pais têm condições de utilizá-la. 
socioeconômicas” (p. 179), diante do aumento do número de famílias monoparentais e de mães trabalhadoras. Através da política do dever de casa "as escolas fazem pesadas exigências quanto à organização da vida familiar e às práticas das mães, o que não é mais razoável, considerando-se as recentes mudanças na estrutura familiar" (p. 178). Subordinando os pais às exigências escolares e impondo-lhes um custo em trabalho, a política do dever de casa tem efeitos perversos: ao “ensinar as famílias suas 'obrigações básicas' de proverem o ambiente doméstico apropriado à aprendizagem”, cria as condições para "culpar as famílias por suas inadequações e então abandonar a responsabilidade de ensinar as crianças dessas famílias" (p. 179). Ameaça exatamente as crianças de famílias pobres, de mães trabalhadoras e chefiadas por mulheres.

A divisão de gênero está presente na separação público/escola-privado/casa no caso da educação, impondo enormes responsabilidades e carga de trabalho às mães. Veja-se este exemplo: As técnicas encarregadas do Plano de Desenvolvimento Escolar (PDE) de uma escola pública municipal de João Pessoa tiveram a idéia de elaborar uma cartilha para mostrar à comunidade escolar como o envolvimento dos pais na aprendizagem dos filhos, em casa e na escola, pode melhorar o seu desempenho na escola e na vida. Criaram uma história em quadrinhos com três episódios. O primeiro traz uma conversa entre duas vizinhas sobre os cuidados com os filhos. Maria diz a Luíza que, mesmo trabalhando o dia inteiro e mesmo sem saber ler, ela pode arranjar um tempinho e sentar com o filho para ver o dever de casa. No segundo episódio, Luíza vai à escola perguntar à professora por que não está enviando dever de casa para o filho. A professora explica que é porque ele não vinha fazendo e aproveita para ensinar a Luíza o seu papel de mãe: ajudar o filho "a gostar mais de estudar e de fazer as tarefas". O terceiro episódio mostra uma reunião de "pais" na escola. Há pais e mães, mas os pais estão em primeiro plano e quem fala é um pai que pede esclarecimentos à professora sobre obstáculos à aprendizagem. Esta explica, então, como "os pais" devem colaborar para superar os obstáculos (João Pessoa, SEDEC, 2002).
A divisão de gênero atravessa as classes sociais. Lareau (1993) demonstrou como as mães de classe média e trabalhadora assumem os encargos educacionais cotidianos, enquanto os pais exercem apenas um papel simbólico no trato com as autoridades escolares. Franco (2002), ao pesquisar famílias de classe média com filhos em escolas particulares de Belo Horizonte, constatou a predominância do envolvimento materno no acompanhamento cotidiano ao dever de casa.

\section{Conclusão: implicações para a eqüidade}

Por que não conceber a educação escolar independentemente da contribuição da família na forma do dever de casa? Por que não seguir a lógica de quanto melhor a qualidade da escola, menos dever de casa? Por que aceitar as sanções implícitas e explícitas do dever de casa sobre a família? Ao conectar escola e família, a política-prática do dever de casa revela contradições, potenciais conflitos e implicações importantes para um projeto de eqüidade e pluralidade cultural via escola, que necessitam ser pesquisadas.

Quando propôs a "abolição do dever de casa", Garrett Redmond apresentou dois argumentos: o dever de casa "ameaçava a vida familiar, privando as crianças de tempo de qualidade com seus pais/mães", e "era injusto porque muitas crianças careciam de computadores, enciclopédias e locais sossegados, de que dispunham aquelas mais afortunadas" (Gill \& Schlossman, 1995, p. B7). Em contraposição, Gill e Schlossman (1995) lembram que "o dever de casa é os olhos e ouvidos dos pais [...] o primeiro e talvez único elo de comunicação que informa aos pais acerca da missão acadêmica da escola [...] [obrigando] os professores a deixar os pais verem o que estão fazendo na sala de aula e quão bem estão desempenhando seu trabalho" (p. B7).

O reconhecimento das implicações do dever de casa no alargamento da defasagem do rendimento escolar e na aprendizagem entre estudantes de classe média e baixa ainda não é voz corrente, mas pode aumentar na medida que as famílias, sobretudo aquelas em situação de desvantagem social, percebam-no como 
uma carga de trabalho imposta pela escola (Rothstein, 2001). Além disso, é importante ressaltar que a prática do dever de casa não repercute diferencialmente no rendimento escolar apenas indiretamente, ao ampliar o tempo de estudo: em muitas escolas e disciplinas (nos Estados Unidos e no Brasil) o dever de casa vale nota ou conta para a nota final (De Carvalho, 2000).

Como nó da parceria família-escola, o dever de casa, portanto, é fundamentalmente uma questão política. Se fosse valorizado ou tivesse condições de ser implementado igualmente por todas as famílias, não necessitaria de regulação formal. Por isso, a política de intensificação do dever de casa pode ser interpretada como um caso de educação da família (de determinadas famílias) e de política cultural, ao submeter os valores educacionais da família à meta de eficácia escolar e aos conceitos prevalentes de sucesso individual. Se, por um lado, o dever de casa poderia ser visto como um incentivo à construção do habitus requerido pelo sucesso escolar e pela empregabilidade, por outro lado, como afirmam Kralovec \& Buell (2000), é uma maneira de remodelar vidas para se adequarem aos requisitos do capitalismo corporativista.

MARIA EULINA PESSOA DE CARVALHO, doutora em currículo, ensino e política educacional pela Michigan State University, é professora no Centro de Educação da Universidade Federal da Paraíba. Publicou: Family-school relations: a critique of parental involvement in schooling (Mahwah, New Jersey, USA: Lawrence Erlbaum Associates; contemplado com o 2000 AESA American Educational Studies Association; Critic's Choice Award); Relações entre família e escola e suas implicações de gênero $(\mathrm{C} a$ dernos de Pesquisa, São Paulo: Fundação Carlos Chagas e Editora Autores Associados, n. 110, julho 2000, p. 143-155). Pesquisa atual: Gênero, educação e formação docente: projeto consciência de gênero na escola; Dever de casa: práticas atuais e visões de professoras, estudantes de pedagogia e mães. E-mail:epcarv@terra.com.br

\section{Referências bibliográficas}

ARBANAS, R. J., (1994). Girls + math + science $=$ choices. A handbook for parents. Marshall, MI: Calhoun Intermediate School District.
BOURDIEU, P., PASSERON, J.-C., (1975). A reprodução: elementos para uma teoria do sistema de ensino. Rio de Janeiro: Francisco Alves.

BOURDIEU, P., (1986). The forms of capital. In: RICHARDSON, J. G. (ed.). Handbook of theory and research for the sociology of education. New York: Greenwood Press, p. 241-258.

BOWDITCH, C., (1993). Response to Michelle Fine's [ap]parent involvement: reflections on parents, power, and urban public schools. Teachers College Record, $\mathrm{n}^{\circ}$ 95, p. 177-181.

BRASIL, Ministério da Educação, INEP, (2003). Brasília: Sala de Imprensa - Notícias do SAEB. Disponível em: <http:// www.inep.gov.br>.

BRASIL, Ministério da Educação, SEF, (2002). Educar é uma tarefa de todos nós. Um guia para a família participar, no diaa-dia, da educação de nossas crianças. Brasília: Secretaria de Ensino Fundamental, Assessoria Nacional do Programa Parâmetros em Ação.

CHUBB, J.E., MOE, T. M., (1990). Politics, markets, and america's schools. Washington, DC: The Brookings Institution.

CLARK, R. M., (1993). Homework-focused parenting practices that positively affect student achievement. In: CHAVKIN, N. F. (ed.). Families and schools in a pluralistic society. Albany: State University of New York Press, p. 85-105.

CORNO, L., (1996). Homework is a complicated thing. Educational Researcher, $\mathrm{n}^{\circ} 25$, p. 27-30.

DE CARVALHO, M. E. P., (2000). Family-school relations : a critique of parental involvement in schooling. Mahwah, New Jersey, USA: Lawrence Erlbaum Associates.

EAST LANSING EDUCATIONAL FOUNDATION, (1996). Student agenda, 1996-1997. East Lansing, MI: East Lansing Public Schools.

EPSTEIN, J. L., PINKOW, L., (1988). A model for research on homework based on U.S. and international studies (Report $\mathrm{n}^{\circ}$ 27). Baltimore, MD: Center for Research on Elementary and Middle Schools. (ERIC Document Reproduction Service $\mathrm{N}$ : ED301323)

ERIC ABSTRACTS DATA BASE, (2000). Homework policy. Diversos títulos. In: DE CARVALHO, M. E. P., (2000). Family-school relations: a critique of parental involvement in schooling. Mahwah, New Jersey, USA: Lawrence Erlbaum Associates, p. 118, 141-149.

FRANCO, M. O. C. de M., (2002). Práticas familiares em relação ao dever de casa: um estudo junto às camadas médias de 
Belo Horizonte. Dissertação de mestrado, Faculdade de Educação da Universidade Federal de Minas Gerais.

GILL, B., SCHLOSSMAN, S., (1995). Homework is a parent's eyes and ears. LA Times, p. B7, 24 January.

HENDERSON, A., BERLA, N. (eds.), (1994). A new generation of evidence: the family is crucial to student achievement. Washington, DC: National Committee for Citizens in Education. HENEVELD, W., (1994). Planejamento e monitoramento da educação primária. Washington DC: Banco Mundial, Departamento Técnico.

HOOVER-DEMPSEY, K. V., SANDLER, H. M., (1997). Why do parents become involved in their children's education? Review of Educational Research, $\mathrm{n}^{\circ}$ 67, p. 3-42.

INGHAM INTERMEDIATE SCHOOL DISTRICT, MSU Office of the Provost, The Capital Area Regional Math and Science Center, (1995). An invitation to sample success: a math/science conference for girls in grade six (Adult Supplement). East Lansing Michigan.

JOÃO PESSOA, Secretaria de Educação e Cultura - SEDEC, (2002). Aprendendo com carinho. João Pessoa: PDE, Escola Municipal Professor Agostinho Fonseca Neto.

KRALOVEC, E., BUELL, J., (2000). The end of homework: how homework disrupts families, overburdens children, and limits learning. In : HOLLOWAY, Lynette. Disrupter of families? A book questions homework. Education life [On-line]. Disponível em: <http://www.nytimes.com/library/national/ 111200edlife-end-edu.html>. Acesso em: 24/11/2000.

LAREAU, A., (1993). Home advantage. London: The Falmer Press.

McCLAIN, M., (1997). Learning in three worlds: an educational ethnography of a Mexican AmERICan family. Unpublished doctoral dissertation, University of Illinois at Chicago.

MURPHY, B., (1996). School district to make detention a family affair [On-line]. Detroit Free Press, October 2. Disponível em: <http://www.freep.com/news/education/qparents25.htm>. Acesso em: 02/10/1996.

NATIONALCOMMISSION ON EXCELLENCE IN EDUCATION, (1983). A nation at risk : the imperative for educational reform. Washington, DC: Department of Education.

NATIONAL EDUCATION GOALS PANEL, (1995). The national education goals report: building a nation of learners. Washington, DC: U.S. Government Printing Office.

NATRIELLO, G., (1997). Hoist on the petard of homework. Teachers College Record, v. 98, n³, p. 572-575.
NOGUEIRA, M. A., ROMANELLI, G., ZAGO, N., (2000). Famí-

lia \& escola: trajetórias de escolarização em camadas médias e populares. Petrópolis: Vozes.

OFFICE OF EDUCATIONAL RESEARCH AND IMPROVEMENT, (1992). Meeting goal 3: how well are we doing? Education research report. Washington, DC: Author. , (1996). A checklist for helping your child with homework. Washington, DC: Author (ERIC Document Reproduction Service N: ED401045).

PAULA, F. A., (2000). Lições, deveres, tarefa, para casa : novas e velhas prescrições para professoras. Dissertação de mestrado. Faculdade de Educação da Universidade de Campinas.

PROGRAMS FOR EDUCATIONAL OPPORTUNITY, (1995). Family math, family science, playtime is science. Michigan: University of Michigan, School of Education, folder.

PROJETO NORDESTE, (1997). Chamada à ação: combatendo o fracasso escolar no Nordeste. Programa de Pesquisa e Operacionalização de Políticas Educacionais. 2 ${ }^{\mathrm{a}}$ ed. Brasília: Banco Mundial/UNICEF.

RODERIQUE, T. W. et al., (1994). Homework: a survey of policies in the United States. Journal of Learning Disabilities, 27, p. 481-487.

ROTHSTEIN, Richard, (2001). Lessons : how to ease the burden of homework for families. Disponível em: <http:// www.nytimes.com/2001/05/23/national/23LESS.html>. Acesso em: $23 / 05 / 2001$.

SCHEMO, D. J., (2000). Report cards are due, only this time for parents [On-line]. The New York Times, November 24. Disponível em: <http://www.nytimes.com/library/national/ 111200edlife-end-edu.html>. Acesso em: 24/11/2000.

SCOTT-JONES, D., (1984). Family influences on cognitive development and school achievement. Review of Research in Education, $\mathrm{n}^{\circ} 11$, p. 259-304.

, (1987). Mother-as-teacher in the families of highand low-achieving low-income black first-graders. Journal of Negro Education, $\mathrm{n}^{\circ}$ 56, p. 21-34.

STEVENSON, H. W., STIGLER, J. W., (1992). The learning gap. New York: Simon \& Schuster.

U.S. DEPARTMENT OF EDUCATION, (1987). What works. Research about teaching and learning. Washington, DC: Author. Recebido em setembro de 2003 Aprovado em novembro de 2003 